\title{
Study of Antioxidant Activity of Biologically Active Compounds Isolated from Green Vegetables by Coupled Analytical Techniques
}

\author{
Magdalena Ligor • Tadeusz Trziszka • \\ Bogusław Buszewski
}

Received: 25 August 2011 / Accepted: 19 January 2012 / Published online: 6 June 2012

(C) The Author(s) 2012. This article is published with open access at Springerlink.com

\begin{abstract}
This study was carried out to determine the total antioxidant activity of selected green vegetables like kale and spinach. The antioxidant activity was expressed in radical scavenging activity (RSA). The generation of the DPPH· (1,1-diphenyl-2-picrylhydrazyl) free radical forms the basis of one of the spectrophotometric methods that has been applied to the measurement of the total antioxidant activity of extracts and solutions of pure substances. Among examined vegetables, spinach showed the highest total antioxidant activity. RSA values for samples of frozen spinach varied from $16.2 \%$ to $42.6 \%$, but RSA for fresh spinach did not exceed $19.8 \%$. Kale extracts were obtained by use of supercritical fluid extraction. The highest antioxidant activity was found for the first fraction of extracts, and it was $14.2 \%$ (for fraction obtained at pressure 258 bar and 5\% methanol addition). Afterwards, lutein belonging to carotenoid group was determined in plant extracts by means of HPLC-UV-VIS. The concentration values of lutein ranged between 0.43 and $0.88 \mathrm{mg} / \mathrm{g}$ for three frozen spinach samples and $0.83 \mathrm{mg} / \mathrm{g}$ for fresh spinach. Lutein, has also antioxidant properties; therefore, RSA was determined for
\end{abstract}

M. Ligor $\cdot$ B. Buszewski $(\bowtie)$

Department of Environmental Chemistry and Bioanalytics,

Faculty of Chemistry, Nicolaus Copernicus University,

Gagarina 7 St.,

87-100 Toruń, Poland

e-mail: bbusz@chem.umk.pl

M. Ligor

e-mail: mada@chem.umk.pl

T. Trziszka

Department of Animal Products Technology and Quality

Management, Faculty of Food Science,

Wrocław University of Environmental and Life Sciences,

Norwida 25/27 St.,

0-375 Wrocław, Poland the standard solutions of lutein. However, the influence of lutein on the RSA values of spinach and kale is relatively low. Spinach, more than other analysed plants had an exceptionally high total polyphenol and flavonoid content.

Keywords Radical scavenging activity P Polyphenols . Flavonoids $\cdot$ Lutein $\cdot$ Green vegetables

\section{Introduction}

Plant and animal tissues maintain complex systems of multiple types of antioxidants, such as glutathione, vitamin $\mathrm{C}$ and vitamin E, as well as enzymes such as catalase, superoxide dismutase and various peroxidases. Low levels of antioxidants or inhibition of the antioxidant enzymes cause oxidative stress and may damage or kill cells (Rice-Evans et al. 1997a; Sies 1997).

Reducing agents such as thiols, polyphenols or carotenoids belong to the group of antioxidants (Sies 1997). The important role of these compounds is to neutralise the free radicals or reactive oxygen species such as the hydroxyl radical $(\cdot \mathrm{OH})$, the superoxide anion $\left(\mathrm{O}_{2}{ }^{--}\right)$and others (Bergamini et al. 2004; Dean et al. 1997; Stoian et al. 1996).

Carotenoids exert the antioxidant actions based on their singlet oxygen quenching properties and ability to trap peroxyl radicals (Paiva and Russell 1999; Stahl and Sies 1996). The first one depends on the number of conjugated double bonds of the molecule and is influenced to a lesser extent by cyclic or acyclic carotenoid groups (Paiva and Russell 1999; Krinsky 1998). Also, cyclic substituents as an end group of polyene hydrocarbon chain (in the structure of carotenoids, as well as xanthophylls like lutein), influence the antioxidant activity of the mentioned compounds. One of the most efficient singlet oxygen quenchers is lycopene; this natural carotenoid contains eleven conjugated and two 
nonconjugated double bonds (Krinsky 1998). Moreover, $\beta$-carotene and xanthophyll are scavengers of peroxyl radicals (Burton and Ingold 1984). $\beta$-carotene exhibits a good radical-trapping antioxidant behaviour only at partial pressures of oxygen. At higher oxygen pressures, it loses its antioxidant activity and shows an autocatalytic, prooxidant effect, particularly at relatively high concentrations. Similar oxygen pressure-dependent behaviour may be shown by other compounds containing many conjugated double bonds (Burton and Ingold 1984). The interaction of carotenoids with peroxyl radicals requires prior presence of unstable $\beta$-carotene radical adduct (Rice-Evans et al. 1997b). These adduct radicals can be shown as being highly resonantly stabilised and are predicted to be relatively unreactive. Afterwards, they may undergo decay to generate nonradical products and may terminate radical reactions by binding to the attacking free radicals (Rice-Evans et al. 1997b). Carotenoids are destroyed during the reaction with peroxyl radicals. This fact confirms the antioxidant activity of carotenoids (Woodall et al. 1997).

It is well known that polyphenols including flavonoids and phenolic acids are characterised by strong antioxidant activity. The flavonoids are a large group of compounds, present in plants, and usually occurring as glycosides. They contain several phenolic hydroxyl functions attached to ring structures. Structural variations within the rings subdivide the flavonoids into several families, such as flavonols (e.g., quercetin and kaempferol), flavones (e.g., luteolin, apigenin and chrysin), flavanols (e.g., catechin) and isoflavones (e.g., genistein). Flavonoids often occur as glycosides, with glycosylation rendering the molecule less reactive towards free radicals; they are more water soluble, so they permit storage in the vacuole (Rice-Evans et al. 1997a). Polyphenols as antioxidants are active in various fields. The antioxidant activity of polyphenols can be determined by the direct reaction with free radicals, the scavenging of free radicals, its reactivity as a hydrogen- or electron-donating agent (which relates to its reduction potential), the fate of the resulting antioxidant-derived radical and its reactivity with other antioxidants, as well as the transition of metalchelating potential (Nijveldt et al. 2001; Amić et al. 2003; Firuzi et al. 2005; Treutter 2006). Especially, the antioxidant activity of flavonoids is based on their potential to form the complex with metal atoms, particularly iron and copper (Treutter 2006). It allows polyphenols to act as preventative antioxidants in terms of inhibiting transition metal-catalysed free radical formation (Rice-Evans et al. 1997a).

Many assays have been introduced for the measurement of the total antioxidant activity of pure compounds (Re et al. 1999; Rice-Evans et al. 1996; Miller and Rice-Evans 1994; Miller et al. 1996; Kono et al. 1995). Each method relates to the generation of a different radical, acting through a variety of mechanisms and the measurement of a range of end points at a fixed time point or over a range (Miller et al. 1996; Kono et al. 1995; Arnao et al. 1990). Two types of approach have been taken into consideration. One of them is the inhibition assays; in that, the extent of scavenging by hydrogen or electron donation of a preformed free radical is the marker of antioxidant activity, as well as assays involving the presence of antioxidant system during the generation of the radical (Re et al. 1999). These assays have been based on different principles and experimental conditions. In general, DPPH (1,1-diphenyl-2-picrylhydrazyl) and ABTS (2,2'-azinobis-(3-ethylbenzothiazoline-6-sulfonic acid)) radical cations are the basis of the spectrophotometric methods that have been applied to the measurement of the total antioxidant activity of solutions of pure substances. The total antioxidant activity can be expressed by the ferric reducing antioxidant power assay (FRAP), oxygen radical absorbance capacity (ORAC), superoxide radical scavenging activity or Trolox equivalent antioxidant activity (Bertoncelj et al. 2007).

The violet-coloured free stable radical DPPH proved to be useful in a variety of investigations including antioxidant properties of natural compounds as well as plant extracts (Ionita 2005). This reagent has a form of a dark-coloured crystalline powder composed of stable free-radical molecules.

The major purpose of this work was to evaluate the radical scavenging activity of various samples of extracts from green vegetables such as kale and spinach. The antioxidant activity of extracts from plants is highly correlated to the concentration of polyphenols including phenolic acids, flavonoids as well as carotenoids. For that reason, the concentrations of these compounds in analysed extracts were determined.

\section{Experimental}

Method Conditions for the Separation and Determination of Polyphenols from Kale Leaves

Supercritical fluid extractor SFE 7680 T (Hewlett Packard, Avondale, PA, USA) was applied. Polyphenols and other compounds were extracted from kale leaves with supercritical fluid and liquid $\mathrm{CO}_{2}$. The solvent modified with methanol (5\%) was applied at the pressures of 100, 175 and 258 bar. Additionally, extraction at 258 bar was made without organic modifier. From every step of extraction, four fractions were obtained (1-mL volume of methanolic extract). Particular supercritical fluid extraction (SFE) conditions include the following: extraction time, $30 \mathrm{~min}$; supercritical fluid, carbon dioxide (purity $99.99 \%$ ) with organic modifier (5\% methanol); fluid temperature, $50{ }^{\circ} \mathrm{C}$; fluid pressures, 100,175 and 258 bar; temperature of extraction, $39^{\circ} \mathrm{C}$; receiver temperature, $65^{\circ} \mathrm{C}$ and trap, a stainless steel tube. For every extraction, $0.2 \mathrm{~g}$ of dried kale leaves was taken. 
Method Conditions for the Separation and Determination of Polyphenols from Spinach Leaves

Fresh and frozen spinach were obtained from a local marketplace. Three samples of frozen spinach (marking I, II, III) came from various manufacturers of frozen food. In the first stages of experiments, samples of frozen spinach (previously kept at room temperature for $3 \mathrm{~h}$ ) were cooked for various times. Samples were prepared by heating $500 \mathrm{mg}$ of each kind of spinach at a temperature of $80^{\circ} \mathrm{C}$ for various time periods (from 1 to $20 \mathrm{~min}$ ). The optimal temperature of heating $\left(80 \pm 1^{\circ} \mathrm{C}\right)$ was obtained by thermocirculator Julabo F25 (Julabo Labortechnik GMbH, Seelbach, Germany). Samples were prepared in a laboratory beaker and stirred occasionally. The temperature of the sample was controlled by means of a thermometer. Each sample of fresh and frozen spinach was cooked separately, and aliquots of them were collected after indicated times $(1,2,3,5,8,10,15$ and $20 \mathrm{~min}$ ). Obtained samples of cooked spinach were dried for 8-24 h at a temperature of $40{ }^{\circ} \mathrm{C}$. Afterwards, samples were ground in a mortar with pestle. The obtained powder of fresh and frozen spinach was used for the preparation of three extracts of each kind of spinach. Five hundred milligrams of each spinach sample was extracted once with $2 \mathrm{~mL}$ methanol. Samples were extracted in a mechanical shaker for $24 \mathrm{~h}$. The extracts were then filtered to remove solid plant debris and kept in a refrigerator (temperature $4{ }^{\circ} \mathrm{C}$ ).

Antioxidant Activity of Plant Extracts and Lutein Solutions

For the determination of the antioxidant activity of kale extracts, DPPH was used. Three millilitres of DPPH solution (4 mg of pure DPPH dissolved in $10 \mathrm{~mL}$ of acetonitrile and $190 \mathrm{~mL}$ of methanol) was mixed with $100 \mathrm{~mL}$ of extract and stored in the darkness for $30 \mathrm{~min}$. After $30 \mathrm{~min}$, absorbance at $\lambda=515 \mathrm{~nm}$ was measured, and blank was prepared by the use of methanol. Because one of the most important constituents of spinach and kale extracts is lutein, we decided to measure antioxidant activity of this compound. The antioxidant activity of lutein (Roth, Karlsruhe, Germany) solutions in the concentration range of 10 to $100 \mu \mathrm{g} / \mathrm{mL}$ of substance was evaluated.

\section{Determination of Total Phenolic Contents in Plants}

According to references (Wettasinghe and Shahidi 1999; Mélo et al. 2006), the total phenolic content was measured spectrophotometrically at $760 \mathrm{~nm}$ using the Folin-Ciocalteu reagent. This reagent is a mixture of phosphomolybdate and phosphotungstate used for the colorimetric assay of polyphenols. Standards of gallic acid in the concentration range of 0.1 to $1.3 \mathrm{mg} / \mathrm{mL}$ were also measured. The results were expressed as gallic acid equivalents (GAE) of dry matter.
Determination of Total Flavonoid Contents in Plants

According to references (Chun-Hua et al. 2007), the total flavonoid content was measured spectrophotometrically at $\lambda=407 \mathrm{~nm}$ using hexamethyltetramine (5\%), methanol, acetic acid (33\%), distilled water and aluminium chloride as reagents. The reaction time of $30 \mathrm{~min}$ was applied. Standards of rutin in the concentration range of 0.1 to $1.0 \mathrm{mg} / \mathrm{mL}$ were also measured. The results were expressed as rutin equivalents (RE) of dry matter.

\section{HPLC-UV-VIS Conditions for Analyses of Spinach} Extracts and Standard Solutions

The spinach extracts were analysed using an Agilent model 1100 liquid chromatographic system consisting of a quaternary pump and a UV-VIS detector (Agilent Technologies, Waldbronn, Germany). Compounds were separated on a Discovery $\mathrm{C}_{18}$ column $(150 \times 4.6 \mathrm{~mm}, 5 \mu \mathrm{m})$ from Supelco (Bellefonte, PA, USA). Methanol:water $(80: 20 v / v)$ was used as eluent A, while ethyl acetate was used as eluent $\mathrm{B}$. The mobile phase was delivered at $1.0 \mathrm{~mL} / \mathrm{min}$ in a gradient mode. The chromatographic conditions are presented in Table 1.

\section{Quantitative Analysis of Plant Extracts by HPLC}

The quantitative analysis was done by means of HPLC with analysis conditions mentioned above. For the calibration procedure, standard mixtures of lutein in methanol were prepared. The concentration of lutein was in the range of $5.0-100.0 \mu \mathrm{g} / \mathrm{mL}$.

Table 1 HPLC-UV chromatographic conditions applied for the determination of lutein in spinach extracts

\begin{tabular}{llll}
\hline Column & $\mathrm{C}_{18}(150 \times 4.6 \mathrm{~mm}, 5.0 \mu \mathrm{m})$ & \\
\hline Mobile phase & A: methanol:water $(80: 20 \mathrm{v} / \mathrm{v})$ & \\
& B: ethyl acetate & \\
Flow rate & $1 \mathrm{~mL} / \mathrm{min}$. & \\
Injection volume & $10 \mu \mathrm{L}$ & & \\
Solvent gradient & Time $(\mathrm{min})$ & $\mathrm{A}(\%)$ & $\mathrm{B}(\%)$ \\
& 0.0 & 80 & 20 \\
& 2.5 & 77.5 & 22.5 \\
& 20.0 & 50 & 50 \\
& 22.5 & 50 & 50 \\
& 24.0 & 20 & 80 \\
& 26.0 & 20 & 80 \\
& 31.0 & 0 & 100 \\
& 34.0 & 0 & 100 \\
& 42.0 & 80 & 20 \\
Detector UV-Vis & $\lambda=450 \mathrm{~nm}$ & & \\
\hline
\end{tabular}


Table 2 Calibration data used for the determination of lutein in plant extracts by HPLC-UV-VIS

\begin{tabular}{|c|c|c|c|c|c|c|c|}
\hline Method & $\begin{array}{l}\text { Concentration range } \\
(\mu \mathrm{g} / \mathrm{mL}, \text { injected })\end{array}$ & $\begin{array}{l}\text { Retention time, } \\
t_{\mathrm{R}}(\min )\end{array}$ & $\begin{array}{l}\text { Calibration } \\
\text { curve }\end{array}$ & $R^{2}$ & $\begin{array}{l}\text { LOD } \\
(\mu \mathrm{g} / \mathrm{mL}, \text { injected })\end{array}$ & $\begin{array}{l}\text { LOQ } \\
(\mu \mathrm{g} / \mathrm{mL}, \text { injected })\end{array}$ & $\begin{array}{l}\text { RSD estimated } \\
\text { for peak areas }(\%)\end{array}$ \\
\hline HPLC-UV-Vis & $5.0-100.0$ & 8.208 & $y=40.189 x-18.907$ & 0.9992 & 0.2 & 0.6 & 5.5 \\
\hline
\end{tabular}

The linearity of the detector response was determined by the square correlation coefficients of the calibration curves generated by three repeated injections of standard solutions at six concentration levels $(5.0-100.0 \mu \mathrm{g} / \mathrm{mL})$. We defined a signal to noise ratio of 3 as a limit of detection (LOD) and a signal to noise ratio of 9 as a limit of quantification (LOQ). All calibration data for lutein, including retention time $\left(t_{\mathrm{R}}\right)$, calibration equations using peak area, linearity with correlation coefficient $\left(R^{2}\right)$ of the calibration curves, LOD and LOQ; precision data as a relative standard deviation (RSD) estimated for peak areas are presented in Table 2. Standard solutions and plant extracts were analysed in triplicate.

\section{Results and Discussion}

One of the most suitable method for the determination of antioxidant activity is the method with DPPH (2,2-diphenyl1-picrylohydrazyl) (Ionita 2005). DPPH is a well-known radical scavenger. Therefore, the rate reduction of a chemical reaction upon addition of DPPH is used as an indicator of the radical nature of that reaction. Because of a strong absorption band centred at about $\lambda=520 \mathrm{~nm}$, the DPPH. radical has a deep violet colour in solution, and it becomes colourless or pale yellow when neutralised. This property allows for visual monitoring of the reaction, and the initial concentration of the radicals can be determined from the change in the optical absorption at $\lambda=520 \mathrm{~nm}$ of DPPH. The scheme of reaction with DPPH is presented in Fig. 1. The antioxidant activity was expressed in radical scavenging activity (RSA). RSA was measured by using Eq. (1)

$\mathrm{RSA}=\frac{A_{\mathrm{DPPH}}-A}{A_{\mathrm{DPPH}}} \times 100 \%$

where $A_{\mathrm{DPPH}}$ is the absorbance values measured for blank and DPPH and $A$ is the absorbance values measured for samples (reaction time $30 \mathrm{~min}$ ).

Kale leaves used for our investigation were from local cultivations and were bought at the marketplace. At first, the sample was dried and crushed. For SFE extraction, dry kale leaves were taken, and extractions were performed at various pressures with organic solvent addition. Moreover, one extraction without methanol was made. Next part of the research was the evaluation of antioxidant activity of extracts which made checking of extraction efficiency possible. Antioxidant activity was assessed by the use of DPPH reagent.

Different antioxidant activities of kale extracts were found when various SFE conditions were applied. The adequate results were found for the first fraction of the obtained SFE extracts. Particularly, RSA values 9.8\% (applied pressure 258 bar, without addition of methanol), $14.2 \%$ (258 bar, $5 \%$ methanol as an organic modifier), $9.0 \%$ (175 bar, 5\% methanol) and 7.0\% (100 bar, 5\% methanol) were found. The data obtained during this experiment are presented in Fig. 2. The higher antioxidant activity of the first fractions can be connected to a higher amount of compounds isolated during the SFE method development. Additionally, it is possible to conclude that the most efficient extraction is observed when 258 bar and 5\% addition of methanol were applied.

During our studies, the antioxidant activity (RSA) of fresh and frozen spinach extracts was examined. Beside one sample, we obtained higher results of RSA for frozen spinach than for fresh spinach. The RSA values obtained for frozen spinach were $16.2 \%, 30.3 \%$ and $42.6 \%$. Meanwhile, the RSA obtained for fresh spinach did not exceed 19.8\%. Particular results obtained during experiments concerning the determination of RSA for fresh and frozen spinach extracts are presented in Fig. 3.

During plant leaves development and expansion, pigmentation increases in order to provide energy through photosynthesis. The physiological age of leaves directly influences colouration and energy production within the plant (leaves, fruits and roots) which is the result of changes in chlorophyll, carotenoid pigments and polyphenols concentrations. The increased colouration in vegetable and fruit tissues associated with maturity is often indicative of

Fig. 1 The scheme of scavenging $\mathrm{DPPH} \cdot$ radical by antioxidant compounds

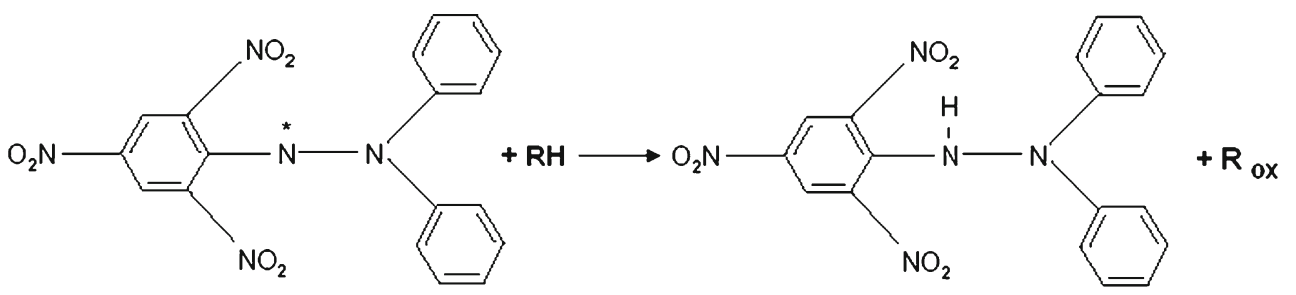


Fig. 2 Comparison of antioxidant activity of kale extracts obtained by the use of SFE extraction method vs. various extraction conditions

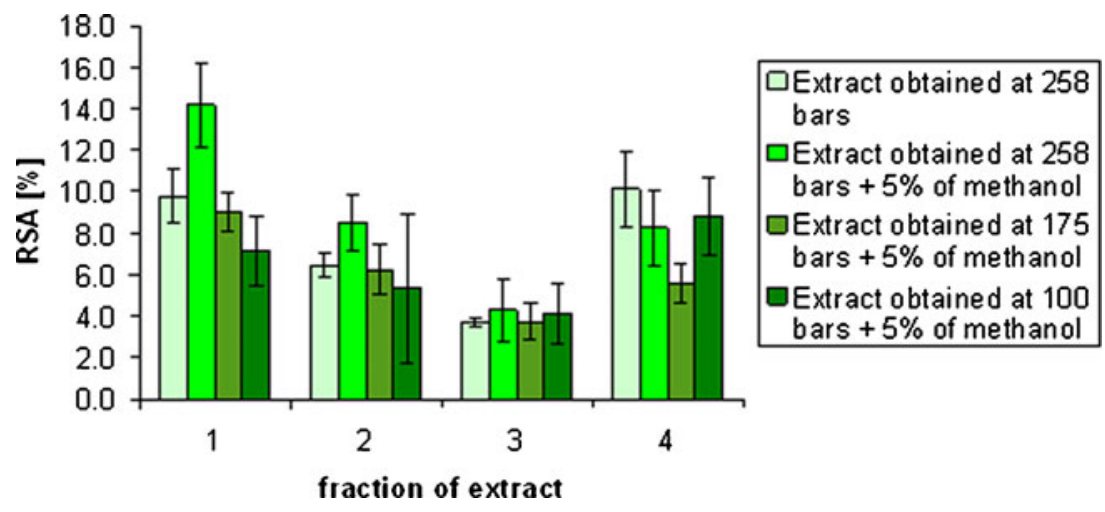

increases in carotenoid concentration (Lefsrud et al. 2007; Gross 1991). It is still unclear what is the progress of changes of carotenoid concentration in leaves during leaf ontogeny and the influence of various cultivation conditions on carotenoids concentration. Carotenoids belong to antioxidants based on their properties and ability to trap free radicals. The first one depends on the number of conjugated double bonds of the molecule and is influenced to a lesser extent by cyclic or acyclic carotenoid groups. Also, cyclic substituents as an end group of polyene hydrocarbon chain (in the structure of carotenoids as well as xanthophylls including lutein) influence the antioxidant activity of the mentioned compounds.

Moreover, many compounds mentioned above influence the antioxidant activity of plant extracts. One of them is lutein, which is a xanthophyll and belongs to the carotenoid group. Radical scavenging activity was evaluated for lutein solutions in the concentration value range of 10 to 100 $\mu \mathrm{g} / \mathrm{mL}$ of substance (Fig. 4). The lower concentration of lutein in the solution gave a RSA value of $6.2 \%$, but for ten times higher concentration value of lutein $(100 \mu \mathrm{g} / \mathrm{mL})$, obtained values of RSA did not exceed $10.0 \%$. Obtained results show that lutein as a component of spinach and kale extracts takes an insignificant part in the total antioxidant activity of these plant extracts.

Many compounds including polyphenols, chlorophylls as well as carotenoids influence the antioxidant activity of plant and natural products extracts. The presence of chlorophylls, carotenoids (e.g., lutein) and others in extracts of both fresh and frozen spinach, as well as kale, was confirmed by HPLC technique. Besides lutein, polyphenols and flavonoids were determined by means of spectrophotometry. Extracts of kale obtained over the most efficient extraction conditions (258 bar and 5\% addition of methanol) were taken for this part of experiments. Particular results obtained after the determination of total polyphenols as GAE and total flavonoids as RE by means of colorimetric method and the concentration of lutein by HPLC-UV-VIS method are presented in Table 3.

The total content of polyphenols in spinach samples varied from 1.823 to $4.946 \mathrm{mg} / \mathrm{g}$ of dry matter; in kale, $0.285 \mathrm{mg} / \mathrm{g}$ polyphenols was found per gram of dry matter. In the presented study, lower concentration of flavonoids than polyphenols in all samples was observed. In particular,
Fig. 3 The antioxidant activity of extracts from spinach

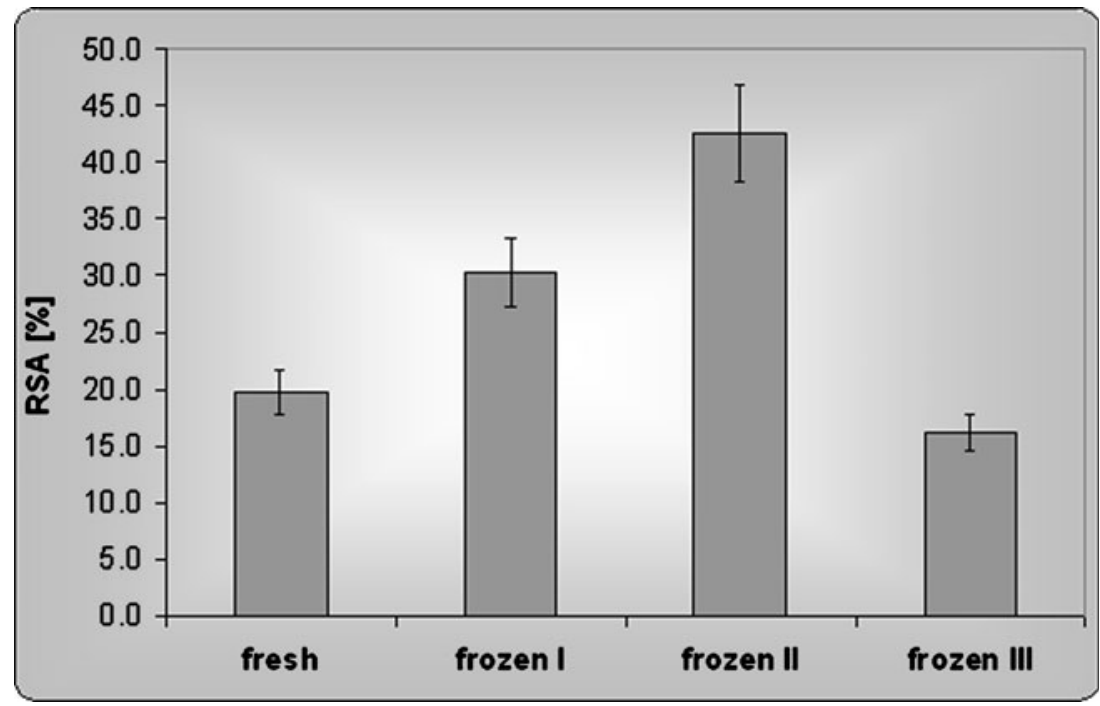


Fig. 4 The antioxidant activity of lutein standards

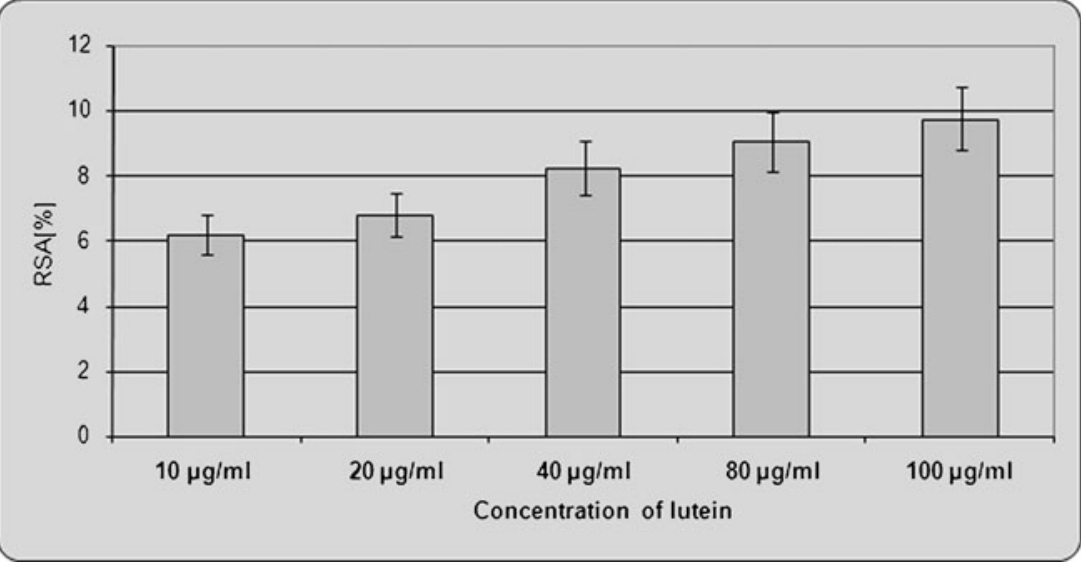

for kale, it was $0.043 \mathrm{mg} / \mathrm{g}$, and for spinach, the concentration values of flavonoids ranged from 0.262 to $0.626 \mathrm{mg} / \mathrm{g}$.

For the determination of lutein, the quantitative analysis of spinach and kale extracts was performed by the use of the external standard method. Data obtained for the standards in concentration values that range from 5.0 to $100.0 \mu \mathrm{g} / \mathrm{mL}$ gave a calibration curve, which was used for the determination of lutein in real samples (extracts from fresh and frozen spinach). Regression coefficients of the calibration curves 0.999 for UV-VIS detection were obtained. LOD and LOQ for UV-VIS detection were $0.2 \mu \mathrm{g} / \mathrm{mL}$ and $0.6 \mu \mathrm{g} / \mathrm{mL}$, respectively. Since the values for LOD and LOQ are low in relation to the usual content of lutein in spinach extracts, we concluded that this method can be used for quantitative analysis. RSD values estimated for the peak areas of the lutein standards did not exceed 5.5\%.

Analyses of extracts from fresh and three samples of frozen spinach gave the following results: the highest concentration values of lutein $0.88 \mathrm{mg} / \mathrm{g}$ for frozen spinach (no. II) and $0.83 \mathrm{mg} / \mathrm{g}$ for fresh spinach were established. For frozen spinach (no. III), the concentration value of lutein was $0.82 \mathrm{mg} / \mathrm{g}$, and the smallest concentration of $0.43 \mathrm{mg} / \mathrm{g}$ for frozen spinach no. I was found. The data were calculated

Table 3 Polyphenol, flavonoid as well as lutein concentrations in samples of green vegetables (calculated for dry matter of sample, mean of triplicate analysis)

\begin{tabular}{llll}
\hline Sample & $\begin{array}{l}\text { Concentration } \\
\text { of polyphenolic } \\
\text { acids (mg GAE/g } \\
\text { dry matter) }\end{array}$ & $\begin{array}{l}\text { Concentration } \\
\text { of flavonoids } \\
\text { (mg RE/g dry } \\
\text { matter) }\end{array}$ & $\begin{array}{l}\text { Concentration } \\
\text { of lutein }(\mathrm{mg} / \mathrm{g} \\
\text { dry matter) }\end{array}$ \\
\hline Kale & $0.285 \pm 0.019$ & $0.043 \pm 0.002$ & $0.691 \pm 0.032$ \\
Fresh spinach & $1.823 \pm 0.040$ & $0.626 \pm 0.013$ & $0.830 \pm 0.047$ \\
Frozen spinach I & $4.946 \pm 0.098$ & $0.370 \pm 0.007$ & $0.428 \pm 0.024$ \\
Frozen spinach II & $4.586 \pm 0.092$ & $0.354 \pm 0.012$ & $0.875 \pm 0.049$ \\
Frozen spinach III & $4.589 \pm 0.098$ & $0.262 \pm 0.008$ & $0.821 \pm 0.039$ \\
\hline
\end{tabular}

for the dry mater of sample (in milligrams/gram). Particular results are also presented in Table 3. The obtained results show that freezing of spinach leaves is not the only way of food storage, but freezing also affects the release of carotenoids from plants. The low temperature influences the destruction of the walls of the plant cells. It is important to obtain the higher concentration of carotenoids in food products. The level of selected discriminants of the chemical composition was compared in frozen species of spinach by Jaworska and Kmiecik (2000). A few parameters including concentration of carotenoids were examined. At every stage of the investigation, differences in the level of the analysed indices were found between the two species in favour of spinach, with the exception of reducing sugars, nitrates and nitrites. In the freezing process, an increase in the level of dry matter and dietary fibre in both species and total nitrogen and nitrites in New Zealand spinach was accompanied by losses in the remaining components. During a 12-month refrigerated storage of these frozen products, the only changes were the reduced content of chlorophylls, an insignificant change of $\beta$-carotene concentration and an increased level of nitrites. In the case of the polyphenol content in frozen vegetables, an increase of their concentration was observed (Ninfali and Bacchiocca 2003). Samples of beet green, spinach, broccoli as well as carrot showed lower phenolic and ORAC values than the fresh vegetables; in the case of onion and celery, values were significantly higher compared to fresh samples.

The detection of the amount of polyphenols and carotenoids must be related to their radical scavenging activity values, as this assay shows the potential health benefit of these compounds, which is very often independent of their absolute quantity. The RSA value is useful in the choice of the plant genotype and also provides information on the optimal preparation way, which is the most important step to be checked before freezing the vegetables to maintain the antioxidant activity of polyphenols and carotenoids. 


\section{Conclusions}

Many compounds including polyphenols, chlorophylls as well as carotenoids influence the antioxidant activity of plant and natural product extracts. Green vegetables like spinach and kale are a rich source of carotenoids and polyphenols. Our investigation confirms that the antioxidant activity of extracts from these green vegetables is correlated to the concentration of carotenoids and polyphenols including phenolic acids and flavonoids. The high level of the content of polyphenol acids and flavonoids in spinach leaves influences the high antioxidant activity.

New aspects of knowledge about green vegetables are the comparison of the carotenoid, polyphenolic acid as well as flavonoid concentration in extracts from spinach and kale. The concentration of lutein belonging to carotenoids was lower than polyphenolic acids but higher than flavonoids. Nevertheless, the presence of lutein in spinach and kale extracts has an insignificant influence on the total antioxidant activity of extracts obtained from these green vegetables.

Acknowledgements The authors wish to thank $Ł$. Starosta, MSc for his technical assistance. The authors thank Prof. Andrius Maruška from the Department of Chemistry, Vytautas Magnus University, Kaunas, Lithuania for the co-operation.

Open Access This article is distributed under the terms of the Creative Commons Attribution License which permits any use, distribution, and reproduction in any medium, provided the original author(s) and the source are credited.

\section{References}

Amić D, Davidović-Amić D, Beslo D (2003) Structure-radical scavenging activity relationships of flavonoids. Croat Chem Acta 76:55-61

Arnao MB, Casas JL, del Rio JA, Acosta M, Garcia-Canovas F (1990) An enzymatic colorimetric method for measuring naringin using 2,2'-azinobis(3-ethylbenzothiazoline-6-sulfonic acid). Anal Biochem $185: 335-338$

Bergamini CM, Gambetti S, Cervellati C (2004) Oxygen, reactive oxygen species and tissue damage. Curr Pharm Des 10:1611-1626

Bertoncelj J, Doberšek U, Jamnik M, Golob T (2007) Evaluation of the phenolic content, antioxidant activity and colour of Slovenian honey. Food Chem 105(2):822-828

Burton GW, Ingold KU (1984) Beta-carotene: an unusual type of lipid antioxidant. Science 224:569-573

Chun-Hua W, Hosakatte NM, Eun-Doo H (2007) Improved production of caffeic acid derivatives in suspension cultures of Echinacea purpurea by medium replenishment strategy. Arch Pharm Res 30:945-949

Dean RT, Fu S, Stocker R, Davies MJ (1997) Biochemistry and pathology of radical-mediated protein oxidation. Biochem $\mathrm{J}$ 324:1-18
Firuzi O, Lacanna A, Petrucci R, Marrosu G, Saso L (2005) Evaluation of the antioxidant activity of flavonoids by "ferric reducing antioxidant power" assay and cyclic voltammetry. Biochim Biophys Acta (BBA) 1721:174-184

Gross J (1991) Pigments in vegetables: chlorophylls and carotenoids. Van Nostrand Reinhold, New York, USA

Ionita P (2005) Is DPPH stable free radical a good scavenger for oxygen active species? Chem Pap 59(1):11-16

Jaworska G, Kmiecik W (2000) Comparison of the nutritive value of frozen spinach and New Zealand spinach. Pol J Food Nutr Sci 9 (4):79-84

Kono Y, Shibata H, Kodama Y, Sawa Y (1995) The suppression of the $\mathrm{N}$-nitrosating reaction by chlorogenic acid. Biochem J 312:947953

Krinsky NI (1998) Overview of lycopene, carotenoids, and disease prevention. Proc Soc Exp Biol Med 218:95-97

Lefsrud M, Kopsell D, Wenzel A, Sheehan J (2007) Changes in kale (Brassica oleracea L. var. acephala) carotenoid and chlorophyll pigment concentrations during leaf ontogeny. Sci Hortic 112:136141

Mélo EA, De Lima VLAG, Maciel MIS, Caetano ACS, Leal FLL (2006) Polyphenol, ascorbic acid and total carotenoid contents $\mathrm{n}$ common fruits and vegetables. Braz J Food Technol 9 (2):89-94

Miller NJ, Rice-Evans CA (1994) Total antioxidant status in plasma and body fluids. Methods Enzymol 234:279-293

Miller NJ, Castelluccio C, Tijburg L, Rice-Evans CA (1996) The antioxidant properties of thioflavines and their gallate estersradical scavengers or metal chelator? FEBS Lett 392:40-44

Nijveldt RJ, van Nood E, van Hoorn D, Boelens PG, van Norren K (2001) Flavonoids: a review of probable mechanisms of action and potential applications. Am J Clin Nutr 74(4):418-425

Ninfali P, Bacchiocca M (2003) Polyphenols and antioxidant capacity of vegetables under fresh and frozen conditions. J Agric Food Chem 51:2222-2226

Paiva SAR, Russell RM (1999) $\beta$-Carotene and other carotenoids as antioxidants. J Am Coll Nutr 18(5):426-433

Re R, Pellegrini N, Proteggente A, Pannala A, Yang M, Rice-Evans C (1999) Antioxidant activity applying an improved ABTS cation radical decolorization assay. Free Radic Biol Med 26:1231-1237

Rice-Evans CA, Miller NJ, Paganga G (1996) Structure-antioxidant activity relationships of flavonoids and phenolic acids. Free Radic Biol Med 20:933-956

Rice-Evans CA, Miller NJ, Paganga G (1997a) Antioxidant properties of phenolic compounds. Trends Plant Sci 2(4):152-159

Rice-Evans CA, Sampson J, Bramley PM, Holloway DE (1997b) Why do we expect carotenoids to be antioxidants in vivo? Free Radic Res 26:381-398

Sies H (1997) Oxidative stress: oxidants and antioxidants. Exp Physiol 82:291-295

Stahl W, Sies H (1996) Lycopene: a biologically important carotenoid for humans? Arch Biochem Biophys 336:1-9

Stoian I, Oros A, Moldoveanu E (1996) Apoptosis and free radicals: mini review. Biochem Mol Med 59:93-97

Treutter D (2006) Significance of flavonoids in plant resistance: a review. Environ Chem Lett 4:147-157

Wettasinghe M, Shahidi F (1999) Evening primrose meal: a source of natural antioxidants and scavenger of hydrogen peroxide and oxygen-derived free radicals. J Agric Food Chem 47:1801-1812

Woodall AA, Britton G, Jackson MJ (1997) Carotenoids and protection of phospholipids in solution or in liposomes against oxidation by peroxyl radicals: relationship between carotenoid structure and protective ability. Biochim Biophys Acta (BBA) 1336:75-586 